\title{
Sustainable and Resilient Design of Interdependent Water and Energy Systems: A Conceptual Modeling Framework for Tackling Complexities at the Infrastructure-Human-Resource Nexus
}

\author{
Weiwei Mo ${ }^{1, *(1)}$, Zhongming Lu ${ }^{2}$, Bistra Dilkina ${ }^{3}$, Kevin H. Gardner ${ }^{1}{ }^{(1)}$, Ju-Chin Huang ${ }^{4}$ and \\ Maria Christina Foreman ${ }^{5}$ \\ 1 Department of Civil and Environmental Engineering, University of New Hampshire, \\ Durham, NH 03824, USA; kevin.gardner@unh.edu \\ 2 School of Environment, Beijing Normal University, Beijing 100875, China; zhongming.lu@bnu.edu.cn \\ 3 School of Engineering, University of Southern California, Los Angeles, CA 90089, USA; \\ bdilkina@cc.gatech.edu \\ 4 Peter T. Paul College of Business and Economics, University of New Hampshire, Durham, NH 03824, USA; \\ Ju-Chin.Huang@unh.edu \\ 5 Volpe National Transportation Systems Center, U.S. Department of Transportation, \\ Washington, DC 20590, USA; Christina.Foreman@dot.gov \\ * Correspondence: Weiwei.mo@unh.edu; Tel.: +1-603-862-2808
}

Received: 5 April 2018; Accepted: 31 May 2018; Published: 2 June 2018

\begin{abstract}
A modeling framework was conceptualized for capturing the complexities in resilience and sustainability associated with integration of centralized and decentralized water and energy systems under future demographic, climate, and technology scenarios. This framework integrates survey instruments for characterizing individual preferences (utility functions) related to decentralization of water and energy infrastructure systems. It also includes a spatial agent-based model to develop spatially explicit adoption trajectories and patterns in accordance with utility functions and characteristics of the major metropolitan case study locations as well as a system dynamics model that considers interactions among infrastructure systems, characterizes measures of resilience and sustainability, and feeds these back to the agent-based model. A cross-scale spatial optimization model for understanding and characterizing the possible best case outcomes and for informing the design of policies and incentive/disincentive programs is also included. This framework is able to provide a robust capacity for considering the ways in which future development of energy and water resources can be assessed.
\end{abstract}

Keywords: infrastructure interdependence; choice experiment; agent-based modeling; system dynamics modeling; spatial optimization; decentralization

\section{Introduction}

During the last decade, a transition in the water and energy supply paradigm is emerging in many places across the nation and the world, which is primarily driven by resource scarcity and environmental concerns. Decentralized and alternative water and energy systems such as rainwater harvesting systems and solar panels are increasingly being integrated into the existing centralized water and energy supply networks to supplement the current supply. While such integrations could potentially increase the resilience of our water and energy supplies to natural and anthropogenic security threats [1], decentralized systems often lack economies of scale and, therefore, could present increased environmental consequences and socioeconomic costs depending on 
technologies and geographic locations [2]. Without careful planning of such integrations and accurate understanding of the infrastructure system interactions and impacts including the important role of human decision-making, unintended consequences are likely to occur. For instance, Germany had to reduce its feed-in tariffs for rooftop solar because a surge in adoption overloaded the existing power grid [3]. Therefore, decision making for future water and energy supply has to take into account complexity at multiple scales and viable solutions can only be obtained with a systematic understanding of these complexities.

\subsection{Complexity at the Centralized Scale}

Centralized systems are the current dominant form of water and energy supply in the US. Management of centralized supplies is inherently complex and many notable issues have surfaced in the last decade. The existing and potential resource stress and shortage contributed by the increasing demand and the water-energy nexus. Increased system failure and management cost results from aging infrastructure. Increasingly stressed system capacity due to population growth and new developments is included as well as more stringent water and wastewater treatment regulations that require substantial cost and space to accommodate and high vulnerability and lack of adaptability to natural threats (e.g., heavy storm, tornado, and extreme heat event), climate change, and decision mistakes [4]. Water and energy systems are highly interdependent one resource cannot be supplied without the other). This "water-energy nexus" underscores the importance of integrated water and energy governance and management, which simultaneously considers multiple objectives related to both water and energy resources (e.g., measures of resilience, sustainability, and social justice in addition to cost). One example of such integrated management is to recognize the varied water-energy interdependence levels of different water and energy supply methods/technologies and to intentionally decouple the interdependence when planning and selecting future sources of supply. Furthermore, much of the US water and energy infrastructure is older and approaching the end of its useful life. An estimated 240,000 water main breaks happen per year in the US with an expected cascading replacement cost of more than $\$ 1$ trillion over the coming decades [5]. Similarly, energy infrastructure is experiencing an increasing number of failures and power interruptions due to extreme weather events and limited maintenance [6]. Centralized supply networks are especially vulnerable to these system failures and interruptions as they lack diversity in source of supply, transmission mode, and system scale.

\subsection{Complexity at the Individual Scale}

A shift in the current water and energy supply paradigm and its influence on water and energy resources depend largely on adoption decisions and consumption behavior at the individual scale. Simulation and prediction of individual decision making is especially difficult given its stochastic and heterogeneous nature and the bounded rationality of individual decision makers [7-9]. However, it is critical for informing policy making and development of incentive/disincentive programs [10]. To obtain such an understanding, some key knowledge needs to be obtained including individual amenities/utilities (i.e., the perceived values to an individual) of specific water and energy technologies, the link of utility value to socioeconomic variables such as socioeconomic status, culture, geographic location of the individual, and individual attitudes towards resilience and sustainability metrics and tradeoffs associated with water and energy technologies. An important component of developing this understanding requires identification of a set of comprehensive resilience (related to the capability to withhold and recover from shocks) and sustainability (related to sustainable use of resources) metrics that are relevant and interpretable to individual decision makers, applicable and tailored to infrastructure systems, and quantitative and measurable to support decision-making about infrastructure systems. Furthermore, decentralized systems change the interaction of end users with their water and energy supply, which may change their consumption and management behavior and alter water and energy conservation dynamics. 


\subsection{Complexity at the Interaction of Multiple Scales}

Complexity also exists at the interaction of multiple scales. While we often purposely separate centralized and decentralized systems conceptually, the difference can be vague and more accurately represents a continuum. Difficult decisions often have to be made on the scale of new construction and/or redevelopment along political boundaries or scales associated with the electrical grid and water management utilities [11-13]. These adoption decisions should ideally reconcile individual interests with the common interests of a community, a city, or even a nation. Finding an ideal solution for a system-wide social optimum can inform the design of management interventions to align individual interests with common interests. Other tradeoffs and synergies may be understood by considering interactions among multiple decentralized water and energy systems. For instance, the need of centralized electricity supply for rainwater harvesting or greywater recycling can be reduced by utilizing the excess electricity generated by onsite solar panels, which could, in turn, increase the utilization rate of solar energy, level energy demand, and reduce energy transmission loss.

\section{Moving Toward Sustainable and Resilient Design of Water and Energy Systems at the Infrastructure-Human-Resource Nexus}

Water and energy infrastructures are essential for human well-being. In turn, preference for and choice of water and energy systems and technologies (a function of price, regulation, availability, among other perceptions) largely influence the transformation of our water and energy supply and infrastructures [14-17]. Additionally, construction and operation of infrastructure systems require substantial resources [18-21] while availability of resources constrains our choice of infrastructure [22-25]. These complex feedbacks and thresholds and the system's emergent behavior typify what we call the "infrastructure-human-resource nexus." Despite being able to name it and provide examples of meaningful interactions, our understanding of the complex thresholds, constraints, and feedbacks embedded in the infrastructure-human-resource systems is still very limited. While many tools such as Choice Experiments (CE; an experiment to learn how individuals value various attributes of a system by analyzing individuals' preferences among a set of hypothetical choices) and agent-based modeling are increasingly applied in the fields of agriculture and renewable energy development, very few applications have been developed to understand decentralized water systems [17,26-28]. There is a need to capture more quantifiable evidence on end users' behavioral patterns as they relate to the design of urban water and energy infrastructures. On the other hand, typical methods that have been used to quantify the water-energy nexus, such as audits [29,30] and life cycle assessments [12,31], are often criticized for their limited consideration of spatially-explicit and temporally-explicit information (e.g., temporal and spatial changes in policy, user adoption, spatial distribution, etc.), negligence of system feedback and stochastic properties (e.g., randomness in system adoption, land development, and utility management), and inability to provide understanding of future trends [32,33]. There is still a lack of a comprehensive modeling framework that captures the dynamic interactions of infrastructure, humans, and resources to guide the future transition/decentralization of our water and energy systems. Therefore, the development of a framework that allows simultaneous simulation, prediction, and assessment of infrastructure sustainability and resilience, human preferences and behavior, and resource availability could greatly transform and advance our current understanding and practice of integrated water and energy management.

\section{A Modeling Framework to Address the Knowledge Gaps}

To address the aforementioned knowledge gaps, we propose a systematic and predictive framework integrating stakeholder CE survey, spatial agent-based modeling, system dynamics modeling, and cross-scale spatial optimization (Figure 1) to provide an enhanced understanding of the resilience and sustainability of future water and energy supplies. Scenarios can be used to test the effectiveness of potential management actions for increasing resilience and decreasing environmental costs. CE survey aims to tackle the complexity at the individual scale by describing individual behavior 
(i.e., choice of water and energy supplies) through mathematical models (i.e., utility functions). Incorporation of CE allows us to evaluate the users' choice of multiple water and energy supply technologies simultaneously including both centralized and decentralized technologies [34]. Utility and behavior functions obtained from the CE survey can inform a coupled spatial agent-based and system dynamics (ASD) model for simulation, prediction, and assessment of various decentralized adoption trajectories and their influences on the existing centralized water and energy supply. For instance, adoption of decentralized greywater recycling systems could potentially reduce the amount of water needed from the centralized drinking water system as well as the amount of wastewater being discharged into the centralized wastewater system. Therefore, the ASD model is a key component that tackles the complexity at the interaction of multiple scales. Specifically, outputs from the spatial agent-based model are primarily adoption rates of the emerged water and energy infrastructure networks. These outputs can be used in a system dynamics model that captures the dynamic water and energy interactions across centralized and individual scales to evaluate the influences of predicted adoption trajectories on infrastructure-human-resource sustainability and resilience. These emergent sustainability and resilience measures further provide feedback to the agent-based model to inform the agents' decision-making in the subsequent discrete time step. The spatial agent-based model is selected because it can account for heterogeneous and adaptive behaviors, information asymmetry, and uncertainty in the adoption of water and energy technologies. The system dynamics model allows simulation of the consequences and constraints of coupled systems, which are comprised of dynamic environmental and socioeconomic processes, signals/feedbacks, and human and governance interventions across salient temporal and spatial scales [35]. Outcomes from the ASD model can be compared to an optimized scenario generated from cross-scale spatial optimization, which creates a scientifically optimal condition based upon local characteristics. This comparison can guide the development of future policy and incentive/disincentive programs.

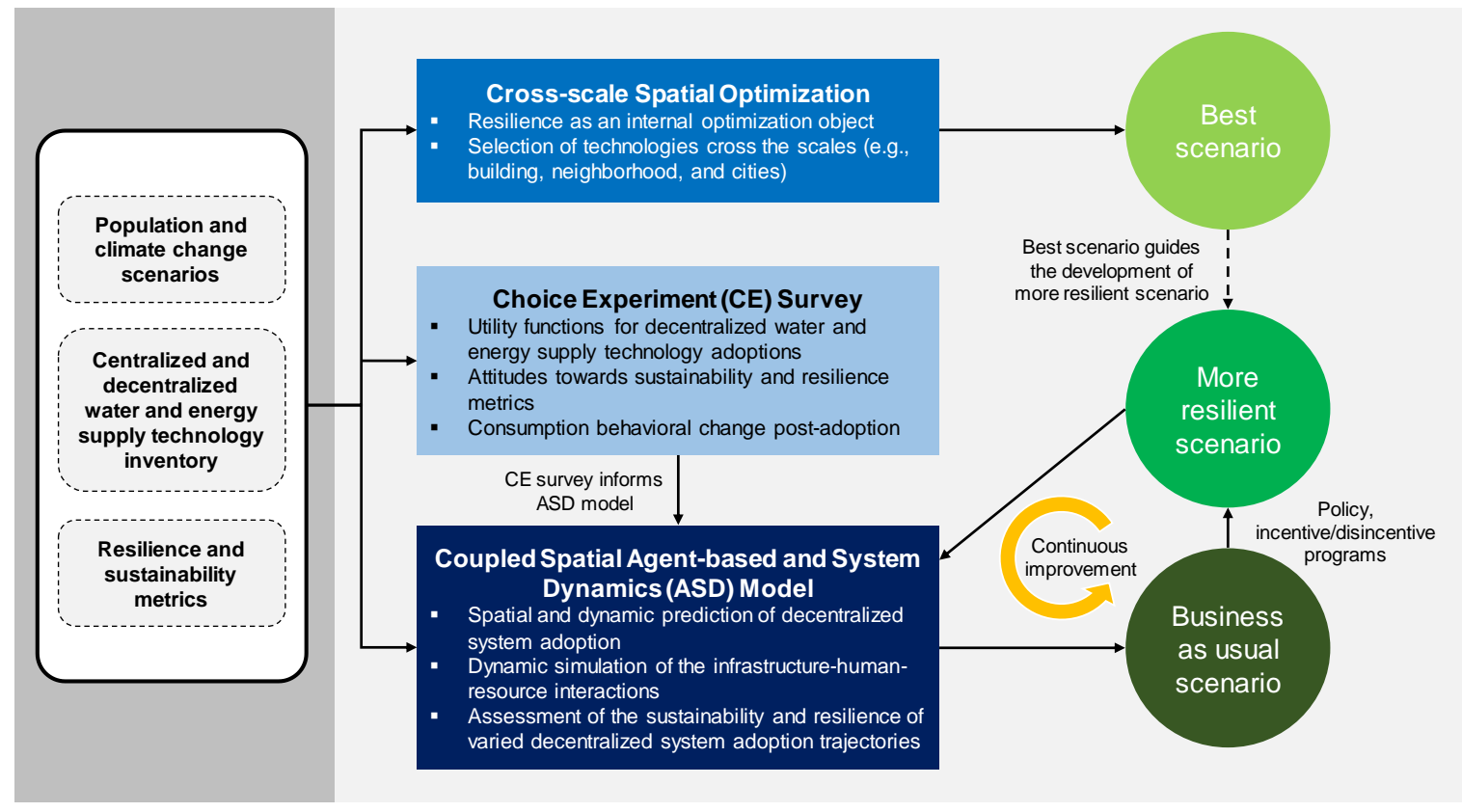

Figure 1. Conceptual framework to address the knowledge gaps at the infrastructure-humanresource nexus. 


\subsection{Addressing Individual Complexity: Elicitation of Stakeholder Preferences and Development of Utility Functions via a CE Survey}

The emergence of a more sustainable and resilient water and energy supply paradigm at the city level depends on how we design urban infrastructure systems that can lead to a higher adoption of appropriate technologies and promote the overall conservation of resources. The CE survey is critical for gathering information in four areas including (1) socioeconomic conditions of survey respondents, (2) attitudes towards the sustainability and resilience measures of the water and energy supply, (3) choices among alternative water and energy supply technologies that are distinguished by different levels of technology attributes, and (4) potential changes to consumption behavior post-adoption. The CE survey can also assist the selection of a combination of sustainability and resilience metrics that are easily interpreted by individual decision makers and influential in their adoption decisions. Such sustainability and resilience metrics should involve environmental, economic, and social aspects. Additionally, they need to be measurable with available data, capable of identifying significant threats and/or drivers for human and environmental well-being, representative of what people care about, and provision of an enhanced understanding of multiple consequences driven by a collection of actions [36]. Figure 2 presents an example set of resiliency and sustainability metrics for evaluating decentralized water and energy systems [37].

\begin{tabular}{l} 
Environment \\
Optimize \\
environmental benefit \\
- Resource \\
resilience \\
- Water quality \\
- Nutrients \\
- Pathogen \\
- Heavy metals \\
- Water quantity \\
- Life cycle water use \\
- Wat savings \\
- Energalance \\
- Life cycle energy use \\
- and savings \\
- Energy balance \\
- Other \\
- Biodiversity \\
- Ecotoxicity \\
\hline
\end{tabular}

Economy
$\begin{aligned} & \text { Maximize economic } \\ & \text { value }\end{aligned}$
- Financial
resilience
- Capital costs
- Planning and design
- Land
- Phasing
- Existing treatment and
collection
- Operational costs
- Pumping
- Treatment
- Maintenance and
repair
- Inspection
- Community
- economic needs
- Availability

Society
Fulfill community
objectives
- Infrastructure
resilience
- Quality of life
- Health
- Outdoor environment
- Built environment
- Aesthetics
- Stability
- Dependable
- Safe
- Equitability
- Serves all equally
- Charges everyone
fairly
- Accessibility
- Easiness to get
- Eermitted and installed
- Easiness of use

Figure 2. Potential resilience and sustainability metrics for water and energy technologies (adapted from WERF, 2014).

\subsection{Intermediate Complexity: Development of a Coupled Spatial Agent-Based and System Dynamics (ASD) Model and Evaluation of Multiple Scenarios}

A tightly coupled spatial agent-based and system dynamics (ASD) model can be used to dynamically simulate and assess the resilience and sustainability of varied decentralized water and energy adoption trajectories. Based on utility and behavioral functions estimated from the CE surveys, an agent-based model can simulate the decision making and behavior of a selection of primary types of agents such as homebuyers, homeowners, home/commercial building developers, utilities, and governments. These types of agents vary in their social functions and act based on their own rules. Utilities provide centralized water and energy services and set their prices. Governments provide incentives or disincentives on decentralized water and energy systems. Home/commercial building developers convert undeveloped land into residential subdivisions or commercial buildings to satisfy housing demand and sell the properties to homebuyers. Developers also decide whether 
or not to adopt decentralized water and energy systems in their new buildings or home designs. Homeowners make decisions on whether or not to redevelop their homes to include decentralized water and energy systems. One advantage of the agent based model is that it captures the dynamic evolution of critical system variables (e.g., decentralized system adoption rates) over time driven by choices made by individual agents at each time step and the dynamics of each climate and population (and, therefore, land use) scenario. The system dynamics model can capture the interaction among water and energy systems and enables the derivation and estimation of resilience and sustainability metrics. In the system dynamics model, all water and energy sources of a region can be identified as critical resource components and simulated as stocks (temporal cumulative levels of source availability) and the inflows (e.g., precipitation, importation, mining) and outflows (e.g., evaporation and consumption/withdrawal) of each stock are identified. Figure 3 illustrates a few selected critical water and energy interactions that could be modeled using the system dynamics model. Multiple sustainability and resilience metrics can be assessed using the system dynamics model such as short-term and long-term water and energy availability and shortages, the degree of water-energy interdependence, and the resilience of water and energy supplies under interruptions of centralized or decentralized systems. The sustainability and resilience measures derived from the system dynamics model can feed back to the agent based model to inform the decision making/behavior of the different types of agents at the next time step.

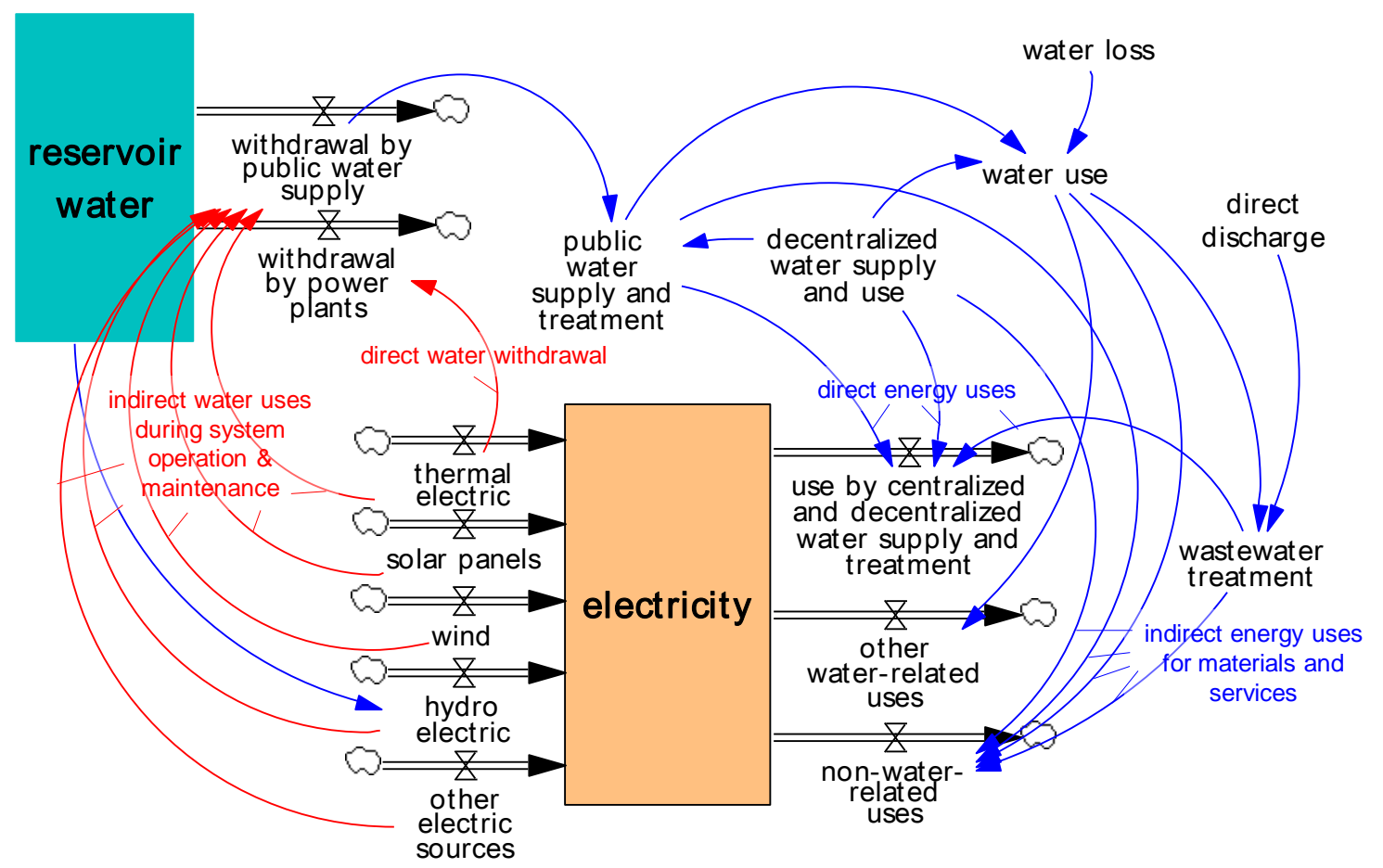

Figure 3. Selected critical interactions between water and energy systems for illustration (red arrows show the causal relationships that determine how much water is used by electricity supply; blue arrows show the causal relationships that determine how much electricity is used by water supply and treatment).

\subsection{Aggregate Complexity: Development of Optimized Scenarios Using a Cross-Scale Spatial Optimization Model}

Adoption decisions concerning water and energy technologies are made on an individual level and by multiple agents, but the outcomes of such decisions are critically interconnected in a complex system with emergent sustainability and resilience properties. In order to guide the design policies and incentive programs, it is critical for understanding and characterizing the possible best case 
outcomes especially because they might not directly result from decisions guided by current individual interests. To find such a social optimum, a cross-scale spatial optimization approach coupled with the system dynamics model can be employed in which many spatial configurations of possible choices of water and energy supply technologies will be considered. In particular, the possibility exists for each community to choose either centralized, community-level decentralized, or home-level decentralized supply technologies for water, energy, or both. Each of such configurations can be evaluated using the system dynamics model to measure the resulting resilience and sustainability metrics. In the complex infrastructure-human-resource systems, it is likely that there is no single configuration that maximizes all relevant metrics or objectives. Therefore, it is reasonable to approach this as a multi-objective optimization problem seeking to find multiple Pareto optimal configurations/solutions that characterize non-dominated tradeoffs between the metrics of interest. The final output of the optimization process will result in several alternative adoption scenarios that optimize different tradeoffs between desired metrics. The values achieved for the resilience and sustainability objectives in these optimized adoption scenarios will provide an upper bound when exploring policy and incentive programs to be evaluated using the ASD model. Additionally, the spatial distributions of the different types of water and energy supply in the optimized adoption configurations can provide critical insights into what desirable properties to promote. For example, one might observe that in certain parts of the city, community-level decentralized water adoption appears more common in optimized configurations, which suggests that a targeted incentive program for this technology could be useful.

\section{Potential Applications of the Modeling Framework}

The modeling framework described in this study can be applied toward investigating the integration of single or multiple types of decentralized water and energy systems into the existing urban landscape. Some examples of such decentralized systems are rainwater harvesting systems, solar panels, and greywater recycling systems. The types of decentralized systems to be included usually depend on local stakeholder interests and research needs. Different types of decentralized systems present different economic and environmental characteristics (e.g., capital investment, savings, carbon footprint, etc.), which could further influence users' preferences of centralized versus decentralized systems as well as their choices among different decentralized technologies. Therefore, a CE survey should be designed to elicit the utility functions of such choices based upon users' socioeconomic characteristics, environmental consciousness, and living conditions. Outcomes of the CE survey will be probabilities of different user groups adopting various types of decentralized systems. These utility functions can be further integrated into the ASD model to simulate the infrastructure-human-resource interactions across individual and centralized scales. The ASD model could run on monthly or yearly steps for a study region based upon the time resolution of data available. At each time step, the spatial agent based model will first predict the spatially distributed adoption rates of different types of decentralized systems based upon local distribution of demographic and household characteristics. The spatial adoption of decentralized systems will then be aggregated to a regional/city level and fed into the system dynamics model. The system dynamics model links the decentralized system adoptions with the centralized water and energy supply systems to investigate their interactions. The type, spatial location, and the amount of decentralized system adoptions can have varied effects on the centralized systems. The sustainability and the resilience of the adoption can be evaluated using metrics such as reduction of greenhouse gas emissions, water storage and availability, the amount of energy used by the water sector, the amount of water used by the energy sector, and more. Adoption and the resulted changes of these metrics could affect utility water and energy prices, overall environmental outcomes, and/or user costs, which could further affect the decision-making of individual users, utilities, and policy makers the next time in the spatial agent-based model. Cross-scale spatial optimization takes use of the spatial parameters such as the distribution networks of the centralized water and energy systems, spatial household characteristics, and flooding risks to create a scientific optimal spatial distribution of 
decentralized system adoptions. Comparison of the ASD and the scientific optimal outcomes could inform the design of incentive/disincentive programs such as carbon tax and infrastructure rebate on certain decentralized systems. Based upon the needs of individual case studies, researchers could choose to apply either the entire modeling framework or a part of it to obtain tailored outcomes for specific decision-making.

The modeling framework is designed to answer questions such as whether integrating decentralized water and energy supply systems into the existing centralized network will increase the resilience and sustainability of water and energy supply, reduce water and energy interdependence, delay or decrease local water and energy shortage and whether policy and management control of decentralized water and energy systems will lead to more resilient and sustainable solutions than the business as usual (BAU) scenario. Other questions include whether policies and incentive programs can reconcile individual interests with community interests to shift the BAU scenario towards a more sustainable and the resilient scenario as well as whether local context (e.g., climate, energy and resources, population etc.) plays a significant role in optimal technologies and degree of decentralization as well as the incentive structure for decentralized water and energy supplies. Overall, this modeling framework is capable of informing decision-making about possible outcomes and tradeoffs in different decentralized water and energy adoption scenarios and critically guide policies and incentives design. It will also build more knowledge about the impact of water-energy interdependence on resilience and sustainability measures, facilitate the planning and design of decentralized systems, and create a more sustainable and resilient infrastructure system for urban communities.

Author Contributions: All authors contributed to the design of the modeling framework and the writing/editing of the paper. Mo led the write-up of this paper and is the lead of the National Science Foundation CRISP Type I Award.

Acknowledgments: We would like to acknowledge the support of the National Science Foundation under a CRISP Type I Award (\#BCS-1638334 and 1638268). Any opinions, findings, and conclusions or recommendations expressed in this material are those of the authors and do not necessarily reflect the views of the National Science Foundation.

Conflicts of Interest: The authors declare no conflict of interest.

\section{References}

1. JFW. Optimizing the Structure and Scale of Urban Water Infrastructure: Integrating Distributed Systems; The Johnson Foundation at Wingspread: Racine, WI, USA, 2014.

2. Fthenakis, V.; Mason, J.E.; Zweibel, K. The technical, geographical, and economic feasibility for solar energy to supply the energy needs of the us. Energy Policy 2009, 37, 387-399. [CrossRef]

3. Wirth, H.; Schneider, K. Recent Facts about Photovoltaics in Germany; Fraunhofer Institute for Solar Energy Systems: Freiburg, Germany, 2013.

4. McGuire, M.J.; Beecher, J.A.; Hanna-Attisha, M.; Masten, S.J.; Rose, J.B. Roundtable—The flint crisis. J. Am. Water Works Assoc. 2016, 108, 26-34. [CrossRef]

5. AWWA. Dawn of the Replacement ERA: Reinvesting in Drinking Water Infrastructure; American Water Works Association: Denver, CO, USA, 2011.

6. ASCE. American Society of Civil Engineers, 2017 Report Card for America's Infrastructure. Available online: http:/ / www.infrastructurereportcard.org/ (accessed on 1 March 2018).

7. Parker, D.C.; Manson, S.M.; Janssen, M.A.; Hoffmann, M.J.; Deadman, P. Multi-agent systems for the simulation of land-use and land-cover change: A review. Ann. Assoc. Am. Geogr. 2003, 93, 314-337. [CrossRef]

8. Berger, T. Agent-based spatial models applied to agriculture: A simulation tool for technology diffusion, resource use changes and policy analysis. Agric. Econ. 2001, 25, 245-260. [CrossRef]

9. Michelsen, C.C.; Madlener, R. Homeowners' preferences for adopting innovative residential heating systems: A discrete choice analysis for germany. Energy Econ. 2012, 34, 1271-1283. [CrossRef] 
10. Faber, A.; Frenken, K. Models in evolutionary economics and environmental policy: Towards an evolutionary environmental economics. Technol. Forecast. Soc. Chang. 2009, 76, 462-470. [CrossRef]

11. Kavvada, O.; Horvath, A.; Stokes-Draut, J.R.; Hendrickson, T.P.; Eisenstein, W.A.; Nelson, K.L. Assessing location and scale of urban nonpotable water reuse systems for life-cycle energy consumption and greenhouse gas emissions. Environ. Sci. Technol. 2016, 50, 13184-13194. [CrossRef] [PubMed]

12. Mo, W.; Zhang, Q. Modeling the influence of various water stressors on regional water supply infrastructures and their embodied energy. Environ. Res. Lett. 2016, 11, 064018. [CrossRef]

13. Hiremath, R.; Shikha, S.; Ravindranath, N. Decentralized energy planning; modeling and application-A review. Renew. Sustain. Energy Rev. 2007, 11, 729-752. [CrossRef]

14. Lu, Z.; Noonan, D.; Crittenden, J.; Jeong, H.; Wang, D. Use of impact fees to incentivize low-impact development and promote compact growth. Environ. Sci. Technol. 2013, 47, 10744-10752. [CrossRef] [PubMed]

15. Levine, J.; Inam, A.; Torng, G.-W. A choice-based rationale for land use and transportation alternatives evidence from boston and atlanta. J. Plan. Educ. Res. 2005, 24, 317-330. [CrossRef]

16. Scarpa, R.; Willis, K. Willingness-to-pay for renewable energy: Primary and discretionary choice of british households' for micro-generation technologies. Energy Econ. 2010, 32, 129-136. [CrossRef]

17. Tapsuwan, S.; Burton, M.; Mankad, A.; Tucker, D.; Greenhill, M. Adapting to less water: Household willingness to pay for decentralised water systems in urban australia. Water Resour. Manag. 2014, 28, 1111-1125. [CrossRef]

18. Grierson, S.; Strezov, V. Life cycle assessment of the microalgae biofuel value chain: A critical review of existing studies. In Proceedings of the Third International Conference on Bioenvironment, Biodiversity and Renewable Energies, BIONATURE 2012, St. Maarten, Netherlands Antilles, 25-30 March 2012; pp. 1-6.

19. Gagnon, L.; Belanger, C.; Uchiyama, Y. Life-cycle assessment of electricity generation options: The status of research in year 2001. Energy Policy 2002, 30, 1267-1278. [CrossRef]

20. Ghimire, S.R.; Johnston, J.M.; Ingwersen, W.W.; Hawkins, T.R. Life cycle assessment of domestic and agricultural rainwater harvesting systems. Environ. Sci. Technol. 2014, 48, 4069-4077. [CrossRef] [PubMed]

21. Collinge, W.O.; Landis, A.E.; Jones, A.K.; Schaefer, L.A.; Bilec, M.M. Dynamic life cycle assessment: Framework and application to an institutional building. Int. J. Life Cycle Assess. 2013, 18, 538-552. [CrossRef]

22. Van Vliet, M.T.; Vögele, S.; Rübbelke, D. Water constraints on european power supply under climate change: Impacts on electricity prices. Environ. Res. Lett. 2013, 8, 035010. [CrossRef]

23. Elliott, J.; Deryng, D.; Müller, C.; Frieler, K.; Konzmann, M.; Gerten, D.; Glotter, M.; Flörke, M.; Wada, Y.; Best, N. Constraints and potentials of future irrigation water availability on agricultural production under climate change. Proc. Natl. Acad. Sci. USA 2014, 111, 3239-3244. [CrossRef] [PubMed]

24. Gleick, P.H. Water and energy. Ann. Rev. Energy Environ. 1994, 19, 267-299. [CrossRef]

25. Berrittella, M.; Hoekstra, A.Y.; Rehdanz, K.; Roson, R.; Tol, R.S. The economic impact of restricted water supply: A computable general equilibrium analysis. Water Res. 2007, 41, 1799-1813. [CrossRef] [PubMed]

26. Giacomoni, M.; Berglund, E. Complex adaptive modeling framework for evaluating adaptive demand management for urban water resources sustainability. J. Water Resour.Plan. Manag. 2015, 141, 04015024. [CrossRef]

27. Giuliani, M.; Castelletti, A. Assessing the value of cooperation and information exchange in large water resources systems by agent-based optimization. Water Resour. Res. 2013, 49, 3912-3926. [CrossRef]

28. Yang, Y.C.E.; Cai, X.; Stipanović, D.M. A decentralized optimization algorithm for multiagent system-based watershed management. Water Resour. Res. 2009, 45. [CrossRef]

29. DOE. The Water-Energy Nexus: Challenges and Opportunities; US Department of Energy: Washington, DC, USA, 2014.

30. Goldstein, R.; Smith, W. Water E Sustainability (Volume 4): Us Electricity Consumption for Water Supply $\mathcal{E}$ Treatment-The Next Half Century; Electric Power Research Institute: Palo Alto, CA, USA, 2002.

31. Mo, W.; Wang, R.; Zimmerman, J.B. An energy-water nexus analysis of enhanced water supply scenarios: A regional comparison of tampa bay, florida and san diego, california. Environ. Sci. Technol. 2014, 48, 5883-5891. [CrossRef] [PubMed]

32. Mo, W.; Wang, H.; Jacobs, J.M. Understanding the influence of climate change on the embodied energy of water supply. Water Res. 2016, 95, 220-229. [CrossRef] [PubMed] 
33. Miller, S.A.; Moysey, S.; Sharp, B.; Alfaro, J. A stochastic approach to model dynamic systems in life cycle assessment. J. Ind. Ecol. 2013, 17, 352-362. [CrossRef]

34. Lu, Z.; Southworth, F.; Crittenden, J.; Dunhum-Jones, E. Market potential for smart growth neighbourhoods in the USA: A latent class analysis on heterogeneous preference and choice. Urban Stud. 2014, 52, 3001-3017. [CrossRef]

35. Kelly, R.A.; Jakeman, A.J.; Barreteau, O.; Borsuk, M.E.; ElSawah, S.; Hamilton, S.H.; Henriksen, H.J.; Kuikka, S.; Maier, H.R.; Rizzoli, A.E. Selecting among five common modelling approaches for integrated environmental assessment and management. Environ. Model. Softw. 2013, 47, 159-181. [CrossRef]

36. Dzombak, D. A berif update on sustainability and roundtable 2015 sessions on sustainability indicators and metrics. In Proceedings of the National Academics of Sciences, Engineering, and Medicine's Workshop-Transition toward Sustainability after 15 Years: Where Do We Stand in Advancing the Scientific Foundation, Newport Beach, CA, USA, 14-15 January 2016.

37. WERF. Water Environment Research Foundation, When to Consider Distributed Systems in an Urban and Suburban Context; WERF: Alexandria, VA, USA, 2014.

(C) 2018 by the authors. Licensee MDPI, Basel, Switzerland. This article is an open access article distributed under the terms and conditions of the Creative Commons Attribution (CC BY) license (http://creativecommons.org/licenses/by/4.0/). 